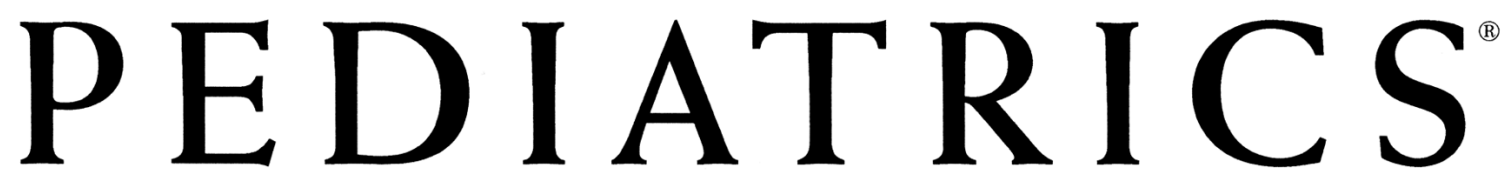

OFFICIAL JOURNAL OF THE AMERICAN ACADEMY OF PEDIATRICS

\title{
A Cluster-Randomized Trial of Screening for Language Delay in Toddlers: Effects on School Performance and Language Development at Age 8
}

Heleen M.E. van Agt, Heleen A. van der Stege, Hanneke de Ridder-Sluiter, Ludo T. W. Verhoeven and Harry J. de Koning Pediatrics 2007;120;1317

DOI: $10.1542 /$ peds.2006-3145

The online version of this article, along with updated information and services, is located on the World Wide Web at: http://pediatrics.aappublications.org/content/120/6/1317.full.html

PEDIATRICS is the official journal of the American Academy of Pediatrics. A monthly publication, it has been published continuously since 1948. PEDIATRICS is owned, published, and trademarked by the American Academy of Pediatrics, 141 Northwest Point Boulevard, Elk Grove Village, Illinois, 60007. Copyright @ 2007 by the American Academy of Pediatrics. All rights reserved. Print ISSN: 0031-4005. Online ISSN: 1098-4275.

\section{American Academy of Pediatrics}




\title{
A Cluster-Randomized Trial of Screening for Language Delay in Toddlers: Effects on School Performance and Language Development at Age 8
}

\author{
Heleen M. E. van Agt, MAa, Heleen A. van der Stege, $\mathrm{PhD}^{\mathrm{b}}$, Hanneke de Ridder-Sluiter, PhD ${ }^{\mathrm{b}}$, Ludo T. W. Verhoeven, PhDc, \\ Harry J. de Koning, MD, PhDa \\ aDepartment of Public Health, Erasmus Medical Center, Rotterdam, Netherlands; ${ }^{b}$ Dutch Foundation for the Deaf and Hard of Hearing Child, Amsterdam, Netherlands; \\ ‘Pedagogical and Educational Sciences, Faculty of Social Sciences, Radboud University Nijmegen, Nijmegen, Netherlands
}

Financial Disclosure: Drs Van de Stege and de Ridder-Sluiter are employed by the Dutch foundation for the Deaf and Hard of Hearing Child, where the VTO language-screening instrument was created; Drs van Agt, Verhoeven, and de Koning have indicated they have no financial relationships relevant to this article to disclose.

\section{ABSTRACT}

OBJECTIVE. The goal of this study was to assess the effects of screening and early treatment of preschool children for language delay on language development and school performance at age 8 .

METHODS. A cluster-randomized, controlled trial and follow-up study of 55 child health centers in 6 geographic regions were conducted from January 2002 to September 2005. A total of 9419 children who were from the general population and aged 15 months at entry were studied. School type end school progress was known for 5406 (57.4\%) children. In the intervention group, a structured screening instrument was conducted twice (at ages 15/18 and 24 months), and usual care was applied in the control group. The screening instrument consisted of a uniform set of questions for the parents and test elements for the child. A positive screen result was followed by multidisciplinary assessments at speech and hearing centers and subsequent early treatment if needed. Percentages of children who attended a special school, repeated a class because of language problems, and scored low on standardized language tests, in intention-to-screen analyses, were measured.

RESULTS. At age $8,2.7 \%$ in the intervention group and $3.7 \%$ in the control group attended a special school, $6.1 \%$ vs $4.9 \%$ had repeated a grade, $8.8 \%$ vs $9.7 \%$ had deficient oral language performance, $4.7 \%$ vs $4.7 \%$ had deficient reading, and $2.8 \%$ vs $4.2 \%$ had deficient spelling.

CONCLUSIONS. Screening toddlers for language delays reduces the number of children who require special education and leads to improved language performance at age 8. Nationwide implementation of the screening might be recommended. www.pediatrics.org/cgi/doi/10.1542/ peds.2006-3145

doi:10.1542/peds.2006-3145

Key Words screening, language delay, preschool children, RCT

Abbreviations

RCT—randomized, controlled trial VTO_VroegTijdige Onderkenning Ontwikkelingsstoornissen RR-relative risk

$\mathrm{Cl}$ - confidence interval

Accepted for publication Jun 19, 2007

Address correspondence to Heleen M. E. van Agt, MA, Department of Public Health Erasmus MC, PO Box 2040, 3000 CA Rotterdam, Netherlands. E-mail: h.vanagt@ erasmusmc.nl

PEDIATRICS (IISN Numbers: Print, 0031-4005; Online, 1098-4275). Copyright $\odot 2007$ by the American Academy of Pediatrics 
C HILDREN'S GENERAL DEVELOPMENT is crucial. In health care, there is much focus on the monitoring of developmental steps in individual young children. ${ }^{1}$ Serious problems in cognitive and/or socioemotional development at school age or adolescence often originate from developmental disorders in childhood, of which language delays are the most prevalent. ${ }^{2-5}$ In a large Dutch sample from the open population, the prevalence of language delays was estimated between $2.4 \%$ and $5.3 \%$ in 3 -year-olds. ${ }^{6}$ Although up to $60 \%$ of language delays at the age of 2 to 3 years probably resolve spontaneously, ${ }^{5}$ some indicate severe and long-lasting language impairment with detrimental effects at later age. ${ }^{7}$ Although effective treatment exists for young children with several underlying causes of language delay, ${ }^{8}$ it is unclear whether systematic screening of language delay at an early age is effective. ${ }^{9}$ Whether screening leads to better language performance as compared with usual practice can be investigated only in a randomized, controlled trial (RCT).

Several studies ${ }^{10-14}$ have evaluated test characteristics of specific screening instruments to detect language delays in preschool children. Only 1 study was set up as an RCT to evaluate the accuracy of a structured test and a parent-led method for language screening among 582 3 -year-old children ${ }^{11}$; however, none of these studies evaluated the effects of screening on language performance at later age.

In the Netherlands, on average, $85 \%$ of all 0 - to 4-year-old children and their parents visit child health centers (for free) at regular times for assessing the child's general development by physicians, including language development. This article describes the effects of a specific screening instrument in a cluster-RCT among 9419 children on school performance and linguistic skills at age 8 in the Netherlands. At this age, children in Dutch schools should normally be in grade 2 of primary school, having had 1 year of reading education. If children are not capable of attending a regular primary school because of learning, behavioral, or health problems, then special education services are offered. Children with severe language delays run a high risk of being placed in special schools or having to repeat a grade. ${ }^{12}$ We hypothesized that the screening would result in a reduction in the proportion of children who need to attend a special school, repeat a year in regular school, or have scores in the lowest percentile of several standardized language tests. We reported previously ${ }^{6}$ that the screening did lead to more earlier diagnoses and treatments in the first 3 years of life, as compared with a control group.

\section{METHODS}

Methods of this cluster-RCT have been published before. ${ }^{6}$ Individual randomization is the ideal design, but we used a cluster trial design to avoid biased results (induced by the alternating use of the specific screening instrument for the intervention children and standard monitoring for the control subjects by 1 physician). Child health care physicians were the units for randomization, and children were the units for analysis.

\section{Randomization}

We asked the child heath care physicians to identify lowand high-socioeconomic neighborhoods within their region. Within the identified socioeconomic strata, each physician was then allocated a number and randomly classified by rolling dice by the trial's manager as alternately intervention or control physician. Physicians in the control group performed the usual monitoring system, which is based on physicians' observation and on questioning the parents in a limited manner without clearcut referral criteria. ${ }^{15}$ The child health center physicians in the intervention group were trained to use the specific screening instrument.

\section{Screening and Diagnosis}

The VroegTijdige Onderkenning Ontwikkelingsstoornissen (VTO; early detection of developmental disorders) Language Screening instrument consisted of questions about the language production, language reception, and interaction of children in the age group 12 to 29 months (Appendixes 1 and 2).6,16,17 With this instrument, the child health center physician in the intervention group interviewed the parents who routinely visited the child health center with their child, which took $\sim 5$ minutes. The complete screening procedure embraced a screening interview at 15/18 months as well as at 24 months. The final score was obtained by adding the scores on both screenings, which ranged between 0 and 7 . When children had a final score of $\leq 2$, they were referred to the general practitioner for additional assessment at a speech and hearing center to confirm language delay and, if so, to assess the underlying causes. ${ }^{6}$ This was done by a uniform protocol of multidisciplinary diagnostic procedures in all regions, which included assessment of language production, language reception, hearing, cognitive development, and socioemotional development. ${ }^{6}$ The cutoff score of the VTO Language Screening instrument was obtained in a pilot study by using the Reynell language comprehension test as gold standard. A cutoff score of $\leq 2$ was found to be the most optimal point, allocating $80 \%$ of the children as having either truepositive or true-negative results. More details on the validity of the VTO, which was proved to be satisfactory, have been published before. ${ }^{6}$

\section{Follow-up}

Follow-up was aimed at all children in both intervention and control groups who according to their date of birth should normally now have been in grade 2 of primary school, in the school years 2001-2002 and 2002-2003, respectively. In the Netherlands, there are separate spe- 
cial schools for children with learning problems, for children with a visual disability, for children who are deaf and hard of hearing and for children with severe speech difficulties, for children with mental and/or physical disabilities, and for children with behavioral difficulties. In January of each school year, we informed all primary schools and special schools in the regions of the study population about the follow-up project. Then we informed the parents by mail and asked them for their written consent to obtain data on their child's linguistic abilities from the school and teacher (plus name and address details of the school and teacher). Two months later, the parents received a questionnaire and, if necessary, a reminder for the informed consent. The parents were asked a number of detailed questions about the history of language problems (age and type of problem) and related treatment. The parent questionnaire contained some questions about background characteristics (number of older brothers/sisters, foreign language spoken at home, educational level of parents, and whether the child had a physical or mental disability/illness), which are known predictors for language development. ${ }^{18,19}$

Schools received a list with the names of the children for which we obtained informed consent from the parents. At the end of the school year, the teachers of these children were asked to fill out a questionnaire and to supply the scores on a set of widely known specified standardized language assessment tests. In case these specified tests were not (yet) applied in a particular school, we included the relevant test material in the mail parcel and asked the teacher whether he or she was willing to administer the test(s) to the child. We also included a book for the classroom and a theater voucher as presents for all teachers (independent of the response). Reminders were sent to all parents and teachers who did not respond in the previous periods.

\section{Participants}

In 6 regions in the Netherlands, 4 regions in the south, 1 in the midsouth, and in 1 large city in the west, 55 physicians of child health centers were randomly assigned. Inclusion started in May 1995 in the 4 regions in the south, in March 1996 in the midsouth region, and in August 1996 in the city in the west. The participating children were those who were between the age of 15 to 24 months in the given inclusion period and were living within the area of the intervention physicians' health care location and those who were living within the area of the control physician $(n=11440)$.

\section{Primary Outcome Measures}

The primary outcome measures (at the individual level) were school performance and linguistic ability at age 8 . School performance embraced school career, defined by the type of school the child was currently attending, and functioning at school, assessed by determining whether the child had repeated a grade. We assessed both oral and written linguistic abilities of the children by means of standardized assessment tests and the independent (blinded toward arms) judgment of teachers.

\section{School Type and Grade}

Data on school type and grade were derived from the parent report on school address details. School type was determined by linking name and address details of the school to the Dutch central registry system, in which each school is allocated a unique number and categorized by school type. Children were assumed to have repeated a grade when their grade was below grade 2 (group 4 in the Netherlands) of primary school, which was the expected grade given the age of the included children.

\section{Standardized Assessment Measures}

Teachers were asked to supply the scores of the individual children with respect to receptive and productive oral and written language usage, consisting of a vocabulary test ${ }^{20}$; spelling ${ }^{21}$ and reading comprehension ${ }^{22}$ tests, which can be administered at group level; and sentence construction ${ }^{23}$ and technical reading ${ }^{24}$ tests, which are to be administered for each child individually. These outcomes are part of the national pupil monitoring system, which is widely used by teachers in Dutch schools to follow the school progress of individual children in primary school. Each test comprises separate units designed for specific measuring moments in the school year. Norm scores consist of 5 levels, which are based on the scores of these tests on the specified measuring moments in a national sample (A: 25\% highest scores; B: $25 \%$ just above the average score; C: $25 \%$ just below the average score; D: $15 \%$ far below the average score; and E: $10 \%$ lowest scores).

\section{Teacher and Parent Questionnaires}

Apart from the standardized tests, the teacher and parent questionnaires also included questions with respect to oral and written linguistic abilities and learning. In addition, the teacher was asked about the child's future development ("Do you think that in the future the child would develop in a normal way?").

\section{Secondary Outcome Measures}

The secondary outcome measure (at the individual level) was the frequency of occurrence of (past) treatment to spur the child's language development, as reported by the parent. Interventions for language difficulties may take many forms because of the broad range of problems as well as the broad range of underlying causes. ${ }^{5}$ To assess the number of children treated for language problems in both intervention and control 
group, we therefore asked the parents the following question: "Has there ever been anything done to spur on your child's language development?" Children were identified as treated for a language problem when parents confirmed the question by answering $\geq 1$ of the following: "Yes, treatment by speech and language therapist/ear, nose, and throat specialist/remedial teacher/ physiotherapist/psychologist/social worker." In addition, parents were asked to report the age around which their child had been treated.

\section{Sample Size}

Under conditions of usual care, we estimated that $\sim 2.5 \%$ of children would be having serious language problems at 8 years (as defined by attending special education). On the basis of the estimated treatment effect sizes from Law et $a l,{ }^{5}$ the observed proportions of different types of language delays among the children whose screening was positive at age 2 , and the number of children who as a result of the screening would be treated for language delay, ${ }^{6}$ we estimated that we could reduce the percentage of serious language delays at age 8 with $20 \%$ in the intervention arm, for a significance level of $5 \%$ ( 1 -sided), a power of $80 \%$, and equal allocation. For a trial with randomization of individual children to be able to detect such a reduction, a minimum of 2925 children in total would need to be recruited. Because we used cluster randomization, we required a larger sample size to compensate for this design effect. The formula $1+[(m-1) \times R]$, where $m=$ the number ot children per cluster, $R=s^{2} b /\left(s^{2} b+s^{2} w\right)$, the intracluster correlation coefficient, is used where $s^{2} b$ is the variance between clusters and $s^{2} w$ is the variance within clusters. ${ }^{25}$ On the basis of the additional assumptions of an estimated intracluster correlation coefficient of 0.005 and an average of 110 eligible and participating children in each cluster $[1+(110-1) \times 0.005=1.55]$, we would need $1.55 \times 2925=4534$ children in total, which is at least 20 clusters in each trial arm.

\section{Analyses}

Comparisons were made between intervention and control groups (intention-to-screen analysis) and between children who completed the full screening procedure (screened at age 15/18 months as well as 24 months) and children who had never been screened by VTO (in this comparison, we excluded children who were screened at 1 age only). The primary outcomes were put to binary variables: regular education/special education, repeating a grade (yes/no), oral and written linguistic abilities according to standardized tests (E level/higher than E level), and normal future development (yes/no) according to the teacher. We analyzed the primary outcome variables by multilevel analysis with 2 levels (cluster and child) by using EGRET 2.0.1 ${ }^{26}$ for logistic regression with distinguishable binomial random effect. To adjust for possible regional differences, we subsequently included region in the model. Although the trial was designed with a 1 -sided hypothesis, ${ }^{27}$ we report the results for 2 -sided $5 \%$ tests for the primary outcomes as well to follow statistical convention.

\section{RESULTS}

Figure 1 shows the flow of children in clusters through the trial. In all, 28 child health center physicians were allocated to the intervention group and 27 physicians to the control group. Thirty-six physicians were not enrolled because of either the very small numbers of children in their care or their inability to meet requirements for participation. During the follow-up period, 15\% of the cohort was not reachable as a result of a change of address. The parents of a total of 9419 children were asked for consent, 5424 (57.6\%) of whom agreed; the parents of 5406 children supplied usable information on school type, and the teachers of 4329 children and the parents of 4281 children completed detailed questionnaires. The response (written consent) in low-socioeconomic neighborhoods was 53.7\% (1447 of 2695), whereas the response in middle- and high-socioeconomic neighborhoods was 58.9\% (3763 of 6388) and $63.9 \%$ (214 of 335; $P=.000)$, respectively. In lowsocioeconomic neighborhoods, the response in the intervention and control groups was $55.6 \%$ and $51.6 \%$ $(P=.015)$, in middle-socioeconomic neighborhoods was $59.4 \%$ and $58.3 \%(P=.537)$, and in high-socioeconomic neighborhoods was $71.4 \%$ and $56.9 \%(P=.006)$, respectively. Baseline and follow-up characteristics of clusters and children were similar between arms (Table 1). Only between regions were there some differences in the number of clusters and children.

Before the age of 2 (start of screening), there were no differences in the cumulative percentages of reported treatments between the intervention and control groups (Table 2). Before age 3, 3.5\% of the children in the intervention group and $2.4 \%$ in the control group had been treated to spur language development $(P=.069)$. Before age 5, the percentage of children who were ever treated was significantly higher in the intervention group than in the control group: $10.8 \%$ vs $8.6 \%(P=$ $.024)$. Before the age of $9,26.5 \%$ of the children in the intervention group and $23.7 \%$ in the control group had been treated to spur language development $(P=.054)$. The intention-to-treat analyses revealed that, in children who were allocated to the intervention arm, the relative risk (RR) for special school attendance was 0.71 and the RR for the lowest level of the spelling test was 0.68 , calculated according to logistic regression with distinguishable binomial random effect, which takes cluster randomization into account (Table 3). After adjustments for regional differences, the RRs were 0.70 (95\% confidence interval [CI]: 0.49-1.02; $P=.063, P=.032$ for 1 -sided testing) and 0.66 (95\% CI: $0.43-1.01 ; P=.054$, 
FIGURE 1

Flowchart of child health physicians (clusters) and children through the trial.
91 eligible clusters (child health cente physicians) $N=91$

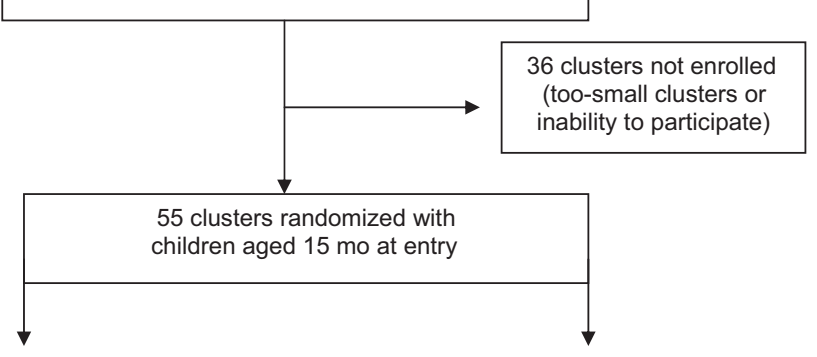

Control group (27 clusters with 4955 children)

No specific screening/usual care $(n=4955)$

Specific screening at $15 / 18$ or 24 mo $(n=560)$

No specific screening/usual care ( $n=2149$ ) (for logistic reasons, holidays, etc)

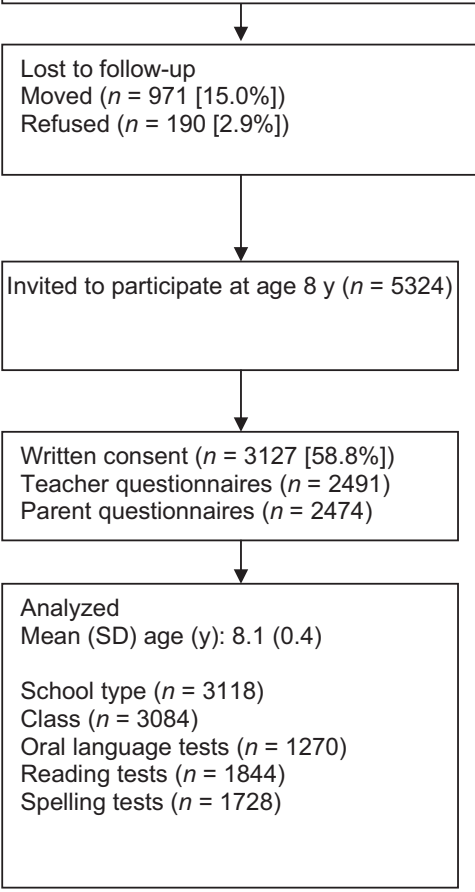

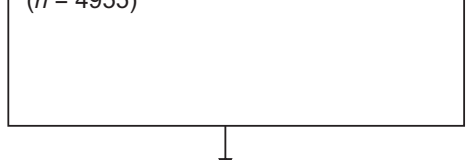

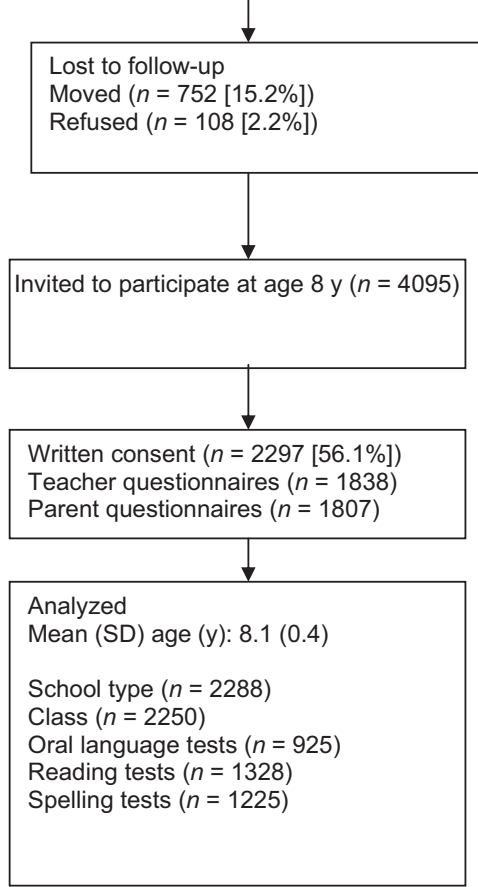

$P=.027$ for 1 -sided testing), respectively. For the other outcomes, no significant differences were found. In the group of children who underwent the complete screening procedure, the RR for special school attendance was 0.75 (95\% CI: $0.62-0.91 ; P=.003$ ) and the RR for lowest level of oral language performance was 0.74 (95\% CI: 0.62-0.90; $P=.002$, adjusted for regional differences; Table 4). For the other outcomes, no significant differences were found.

\section{DISCUSSION}

We have shown that early detection of language delays in toddlers at child health care centers by means of a specific screening instrument followed by early treatment can reduce the percentage of children who attend a special school at 8 years by $30 \%$. At the same time, the number of children with spelling problems was reduced by $33 \%$. Screened children seemed to have fewer problems with oral linguistic skills. The screening led to more treatments and support in the preschool period.

Parent report on school type and grade proved to be reliable; only $<1 \%$ of the school addresses were found to be incorrect. With the help of the teachers, the children's linguistic abilities were measured by standardized tests, which were validated and proved to be reliable in previous research. ${ }^{28}$ Only a small proportion of teachers were not familiar with the tests; however, this proportion did not differ between the intervention and control groups, so this could not have been a potential bias. Importantly, none of the teachers knew whether the child belonged to the intervention or control group. Special school attendance can be considered to be a valid 


\begin{tabular}{|c|c|c|c|c|c|}
\hline \multirow[t]{2}{*}{ TABLE 1} & \multicolumn{5}{|c|}{$\begin{array}{l}\text { Characteristics of Child Health Care Physicians (Clusters) and Children: Initially Recruited and } \\
\text { Follow-up at Age } 8\end{array}$} \\
\hline & Characteristic & $\begin{array}{l}\text { Intervention } \\
\text { Group }\end{array}$ & $\begin{array}{l}\text { Control } \\
\text { Group }\end{array}$ & Total & $P$ \\
\hline \multicolumn{6}{|c|}{ Initially recruited } \\
\hline \multicolumn{6}{|c|}{ Clusters } \\
\hline Total & No. of clusters & 28 & 27 & 55 & - \\
\hline No. of & children per cluster, mean (SD) & $224(173)$ & $184(133)$ & $204(155)$ & - \\
\hline \multicolumn{6}{|c|}{ Region, No. of clusters (children) } \\
\hline & th part (south) & $4(1153)$ & $4(1141)$ & $8(2294)$ & - \\
\hline & th part (mid) & $5(1537)$ & $4(957)$ & $9(2494)$ & - \\
\hline & th part (southwest) & $3(824)$ & $2(466)$ & $5(1290)$ & - \\
\hline & th part (southeast) & $3(1166)$ & $4(1084)$ & $7(2250)$ & - \\
\hline & Asouth & $5(1409)$ & $8(1210)$ & $13(2619)$ & - \\
\hline & ge city in west part & $8(396)$ & $5(97)$ & $13(493)$ & - \\
\hline \multicolumn{6}{|c|}{ Socioeconomic neighborhood, No. of clusters } \\
\hline Lo & & 5 & 6 & 11 & - \\
\hline & ddle & 21 & 20 & 41 & - \\
\hline $\mathrm{Hic}$ & & 2 & 2 & 4 & - \\
\hline \multicolumn{6}{|c|}{ Children } \\
\hline Total & & 6485 & 4755 & 11440 & - \\
\hline Male, & & 50.1 & 52.0 & 50.9 & .045 \\
\hline \multicolumn{6}{|c|}{ Follow-up age 8} \\
\hline Total & & 3127 & 2297 & 5424 & - \\
\hline Age, me & $\operatorname{an}(S D), y$ & $8.1(0.4)$ & $8.1(0.4)$ & $8.1(0.4)$ & .862 \\
\hline Male, \% & & 49.9 & 50.1 & 50.0 & .926 \\
\hline \multicolumn{6}{|c|}{ Parental questionnaire } \\
\hline Physi & al disability/illness, \% & 6.8 & 7.8 & 7.2 & .226 \\
\hline \multicolumn{5}{|c|}{ Maternal education, $\%$} & .196 \\
\hline Low & & 14.6 & 16.6 & 15.4 & - \\
\hline Intern & hediate & 59.9 & 59.2 & 59.6 & - \\
\hline High & & 25.5 & 24.3 & 25.0 & - \\
\hline \multicolumn{5}{|c|}{ Paternal education, $\%$} & .921 \\
\hline Low & & 18.7 & 18.8 & 18.8 & - \\
\hline Intern & nediate & 45.5 & 44.8 & 45.2 & - \\
\hline High & & 35.8 & 36.3 & 36.0 & - \\
\hline Foreign & anguage in family, $\%$ & 9.5 & 10.7 & 10.0 & .208 \\
\hline Children & in family, $n$ (SD) & $2.31(0.84)$ & $2.26(0.82)$ & $2.28(0.83)$ & .053 \\
\hline
\end{tabular}

measure of school performance, because only children with severe educational problems attend such schools in the Netherlands. It should be noted, however, that problems other than language might be the only reason for special school entrance (eg, behavioral problems); therefore, we took account of possible differences in the re- ferral policy for special education by adjusting for regional differences.

At 3 years of age, the VTO screening had been found to result in larger proportions of children with diagnosed and/or treated language problems. ${ }^{6}$ In this study, parents in the intervention group reported significantly more

TABLE 2 Children Being Treated Per Age (Parent Questionnaire)

\begin{tabular}{|c|c|c|c|c|}
\hline $\begin{array}{c}\text { Age at Which Child Was Treated } \\
\text { to Spur Language } \\
\text { Development, } y^{\mathrm{a}}\end{array}$ & $\begin{array}{l}\text { Intervention }(n=2192) \\
\quad \text { Cumulative } n(\%)\end{array}$ & $\begin{array}{l}\text { Control }(n=1601), \\
\text { Cumulative } n(\%)\end{array}$ & $\begin{array}{l}\text { Total }(N=3793), \\
\text { Cumulative } n(\%)\end{array}$ & $P$ \\
\hline 2 & $26(1.2)$ & $20(1.2)$ & $46(1.2)$ & .881 \\
\hline 3 & $76(3.5)$ & $39(2.4)$ & $115(3.0)$ & .069 \\
\hline 4 & $141(6.4)$ & $85(5.3)$ & $226(6.0)$ & .165 \\
\hline 5 & $237(10.8)$ & $137(8.6)$ & $374(9.9)$ & .024 \\
\hline 6 & 331 (15.1) & $214(13.4)$ & $545(14.4)$ & .134 \\
\hline 7 & $452(20.6)$ & $296(18.5)$ & 748 (19.7) & .107 \\
\hline 8 & $557(25.4)$ & $364(22.7)$ & $921(24.3)$ & .060 \\
\hline 9 & $581(26.5)$ & $380(23.7)$ & $961(25.3)$ & .054 \\
\hline
\end{tabular}

a Has there ever been anything done to spur on your child's language development (by speech language therapist; ear, nose, and throat specialist, remedial teacher, physiotherapist, psychologist, or social worker)? 


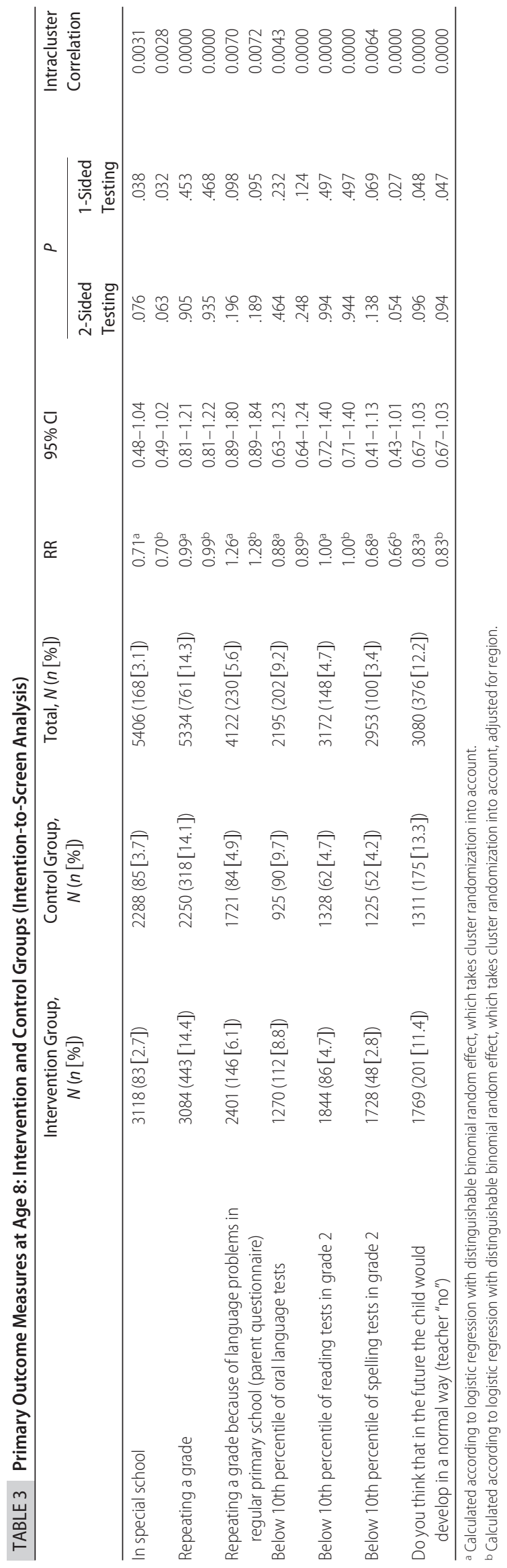

treatments related to language development in their child's preschool period, in particular around the time of school entrance. Given the time period, parents might be remembering their child's being treated for language problems rather than the occurrence of (past) language problems; however, these results must be evaluated with caution, because we did not collect detailed data on language problems from specialists as we did previously. ${ }^{6}$

The parents of $57 \%$ of all eligible children participated in the follow-up study. Given that we addressed an open population and asked to sign for consent, the response is moderate but acceptable. The response (proportion of written consent) was only slightly lower in low-socioeconomic neighborhoods than in middle- and high-socioeconomic neighborhoods, so we think that the sample is still representative of the total population. The response of the schools and teachers was very high $(82 \%)$. Although small but significant differences in response between intervention and control groups within low- and high-socioeconomic neighborhoods were found, this could not have been a potential bias of the results because we did not find any significant differences in the distribution of educational level of the parents between the intervention and control groups. In addition, there were no substantial differences in loss to follow-up and nonresponse between the study arms and hence could not have biased the observed differences in outcomes between the intervention and control groups either.

The population visiting the child health centers in the Netherlands is not a selected group: $\sim 95 \%$ of all parents visit these centers during the first year of their child's life. ${ }^{6}$ Only children who have severe disabilities diagnosed at birth and need specialized care during their first year are seen by pediatricians and rarely visit a child health center.

Most studies ${ }^{11-14,29,30}$ on early detection of language problems concluded that it is possible to identify children with language problems at an early stage in the preschool period, sometimes by 2 -step screening methods. These studies focused on the test characteristics of the screening instrument. Comparisons across studies are difficult because there is no generally accepted definition of language problems or gold standard, and methods of assessment differ. ${ }^{5}$ The most valid method would be clinical examination; however, this is not feasible in population-based studies. Apart from the sensitivity and specificity of the instrument, it is important for economic reasons to consider the proportion of children who have positive screening results and require additional assessment. Previously, $\mathrm{we}^{6}$ found that the sensitivity of the VTO instrument, resulting in $2.4 \%$ of positive screenings, was between $25 \%$ and $52 \%$, depending on the assumed prevalence of language problems, which was based on either specialist or parent report. Some studies ${ }^{31}$ found higher sensitivity measures at the expense of high referral rates. One RCT reported that the sensitivity of a structured test and a parent-led method was, respectively $66 \%$ and $56 \%{ }^{11}$; however, the applica- 
TABLE 4 Primary Outcome Measures at Age 8: Screened With Specific Instrument (Completed Screens) and Never Screened With Specific Instrument

\begin{tabular}{|c|c|c|c|c|c|c|c|c|}
\hline & \multirow[t]{2}{*}{ Screened } & \multirow[t]{2}{*}{ Not Screened } & \multirow[t]{2}{*}{ Total } & \multirow[t]{2}{*}{ RR } & \multirow[t]{2}{*}{$95 \% \mathrm{Cl}$} & \multicolumn{2}{|c|}{$P$} & \multirow{2}{*}{$\begin{array}{l}\text { Intracluste } \\
\text { Correlation }\end{array}$} \\
\hline & & & & & & $\begin{array}{l}\text { 2-Sided } \\
\text { Testing }\end{array}$ & $\begin{array}{l}\text { 1-Sided } \\
\text { Testing }\end{array}$ & \\
\hline \multirow[t]{2}{*}{ In special school } & $1980(41$ [2.1]) & 3142 (114[3.6]) & $5122(115[3.0])$ & $0.75^{\mathrm{a}}$ & $0.62-0.92$ & .005 & .003 & 0.0044 \\
\hline & & & & $0.75^{b}$ & $0.62-0.91$ & .003 & .002 & 0.0024 \\
\hline \multirow[t]{2}{*}{ Repeating a grade } & 1961 (265 [13.5]) & 3092 (447 [14.5]) & $5053(712[14.1])$ & $0.95^{\mathrm{a}}$ & $0.86-1.04$ & .256 & .129 & 0.0000 \\
\hline & & & & $0.95^{b}$ & $0.86-1.04$ & .282 & .141 & 0.0000 \\
\hline \multirow{2}{*}{$\begin{array}{l}\text { Repeating a grade because of language } \\
\text { problems (in regular primary school) }\end{array}$} & 1585 (92 [5.8]) & $2469(142[5.8])$ & 4054 (234 [5.8]) & $0.98^{\mathrm{a}}$ & $0.84-1.15$ & .821 & .411 & 0.0051 \\
\hline & & & & $0.98^{b}$ & $0.84-1.15$ & .830 & .415 & 0.0056 \\
\hline \multirow{2}{*}{$\begin{array}{l}\text { Below 10th percentile of oral language } \\
\text { tests }\end{array}$} & $817(55[6.7])$ & $1271(137[10.8])$ & 2088 (192 [9.2]) & $0.74^{a}$ & $0.62-0.90$ & .002 & .001 & 0.0083 \\
\hline & & & & $0.74^{b}$ & $0.62-0.90$ & .002 & .001 & 0.0070 \\
\hline \multirow{2}{*}{$\begin{array}{l}\text { Below } 10 \text { th percentile of reading tests } \\
\text { in grade } 2\end{array}$} & $1188(55$ [4.6]) & $1829(88$ [4.8]) & 3017 (143 [4.7]) & $0.98^{\mathrm{a}}$ & $0.82-1.16$ & .819 & .410 & 0.0000 \\
\hline & & & & $0.98^{\mathrm{b}}$ & $0.82-1.16$ & .791 & .396 & 0.0000 \\
\hline \multirow{2}{*}{$\begin{array}{l}\text { Below } 10 \text { th percentile of spelling tests } \\
\text { in grade } 2\end{array}$} & $1127(30[2.7])$ & $1685(65$ [3.9]) & $2812(95[3.4])$ & $0.87^{\mathrm{a}}$ & $0.68-1.12$ & .287 & .144 & 0.0099 \\
\hline & & & & $0.84^{b}$ & $0.66-1.08$ & .175 & .088 & 0.0032 \\
\hline \multirow{2}{*}{$\begin{array}{l}\text { Do you think that in the future the child } \\
\text { would develop in a normal way } \\
\text { (answer teacher "no") }\end{array}$} & $1124(221$ [12.3]) & $1793(134[11.9])$ & 2917 (355 [12.2]) & $0.98^{\mathrm{a}}$ & $0.88-1.10$ & .745 & .373 & 0.0000 \\
\hline & & & & $0.98^{b}$ & $0.88-1.10$ & .770 & .385 & 0.0000 \\
\hline
\end{tabular}

a Calculated according to logistic regression with distinguishable binomial random effect, which takes cluster randomization into account.

${ }^{b}$ Calculated according to logistic regression with distinguishable binomial random effect, which takes cluster randomization into account, adjusted for region.

bility of these results to the general population is questionable because the sample came from a deprived area. Moreover, according to Laing et al, ${ }^{11}$ the low uptake and high attrition rate had probably biased the results toward overestimating the performance of the screening test. Laing et al did not recommend formal screening on language problems, because they considered the sensitivity of the structured test not to be substantially higher than that of the parent-led method; however, we think that the sensitivity of the VTO screening instrument pertains to a realistic and acceptable figure, given the low referral rate and the young age of the children. ${ }^{6}$ Most important, this is the first study to evaluate the effects of an early language screening program in an RCT, to assess whether the specific screening procedure leads to extra diagnosed and/or treated language problems and, most important, to extra "health" benefits at later age as compared with usual practice. ${ }^{9}$ After all, the results of an RCT allow inferences about causal relationships between the screening and the effects.

\section{CONCLUSIONS}

We have shown that an early language screening program including a protocol of multidisciplinary diagnostic procedures can reduce special school entrance and linguistic problems. Nationwide implementation of the intervention as part of routine monitoring of children's general development can be recommended.

\section{ACKNOWLEDGMENTS}

This study was funded by the Health Care Insurance Board (College voor zorgverzekeringen).

We are grateful to the schools, teachers, parents, and children who participated in this study; Anna Brandt, Sandra Laurier, Toon Juttmann, Marianne
Quak, and Dick Slof for assistance with the data collection and computer input of the data; Jan Alberts for designing the procedures for data management and data processing; and Carin Reep-van den Bergh, MA, and Paul van der Maas, MD, PhD, for general and methodologic support.

\begin{tabular}{cc} 
APPENDIX 1 Items of the VTO Language Screening Instrument ${ }^{17}$ \\
\hline Age, mo
\end{tabular}




\section{APPENDIX 2 Question 1 of the Screening Instrument at 24 Months of $\mathrm{Age}^{17}$}

Let us start with the little sounds and words of (name of the child)
Thinking about the past period, can you tell me:
a. How does (name of the child) call people in his/her proximity?
b. What does (name of the child) say if (name of the child) wants
something to eat or drink?
c. What does (name of the child) say if (name of the child) wants
to play with toys?
Possible answer categories
Sentence
Word or name
Calls by sound or indicates; for instance, br = car
Daddy, mama
Pointing out with sounda
Pointing out without sounda
Not indicating anything
a If the parent's answer is "pointing out," then ask, "Does (name of the child) make any sounds
while pointing?"
b Does (name of the child) make little sounds? If yes, then what are these sounds like?

\section{REFERENCES}

1. First LR, Palfrey JS. The infant or young child with developmental delay. $N$ Engl J Med. 1994;330:478-483

2. Felsenfeld S, Broen PA, McGue M. A 28-year follow-up of adults with a history of moderate phonological disorder: educational and occupational results. J Speech Hear Res. 1994;37: 1341-1353

3. Stothard SE, Snowling MJ, Bishop DV, Chipchase BB, Kaplan CA. Language-impaired preschoolers: a follow-up into adolescence. J Speech Lang Hear Res. 1998;41:407-418

4. Johnson CJ, Beitchman JH, Young A, et al. Fourteen-year follow-up of children with and without speech/language impairments: speech/language stability and outcomes. J Speech Lang Hear Res. 1999;42:744-760

5. Law J, Boyle J, Harris F, Harkness A, Nye C. Screening for speech and language delay: a systematic review of the literature. Health Technol Assess. 1998;2:1-184

6. de Koning HJ, de Ridder-Sluiter JG, van Agt HM, et al. A cluster-randomised trial of screening for language disorders in toddlers. J Med Screen. 2004;11:109-1 16

7. Miniscalco C, Nygren G, Hagberg B, Kadesjo B, Gillberg C. Neuropsychiatric and neurodevelopmental outcome of children at age 6 and 7 years who screened positive for language problems at 30 months. Dev Med Child Neurol. 2006;48: 361-366

8. Law J, Garrett Z, Nye C. The efficacy of treatment for children with developmental speech and language delay/disorder: a meta-analysis. J Speech Lang Hear Res. 2004;47:924-943

9. Nelson HD, Nygren P, Walker M, Panoscha R. Screening for speech and language delay in preschool children: systematic evidence review for the US Preventive Services Task Force. Pediatrics. 2006;117(2). Available at: www.pediatrics.org/cgi/ content/full/117/2/e298

10. Klee T, Carson DK, Gavin WJ, Hall L, Kent A, Reece S. Concurrent and predictive validity of an early language screening program. J Speech Lang Hear Res. 1998;41:627-641

11. Laing GJ, Law J, Levin A, Logan S. Evaluation of a structured test and a parent led method for screening for speech and language problems: prospective population based study. BMJ. 2002;325:1152

12. Westerlund M, Sundelin C. Can severe language disability be identified in three-year-olds? Evaluation of a routine screening procedure. Acta Paediatr. 2000;89:94-100

13. Mattsson CM, Marild S, Pehrsson NG. Evaluation of a language-screening programme for 2.5-year-olds at child health centres in Sweden. Acta Paediatr. 2001;90:339-344

14. McGinty C. An investigation into aspects of the Mayo early language screening test. Child Care Health Dev. 2000;26: $111-128$

15. Brouwers-de Jong EA, Burgmeijer RJ, Laurent de Angulo MS, eds. Monitoring development at the Child Health Center: Manual for the Revised Van Wiechen Examination [in Dutch]. Assen, Germany: Van Gorcum; 1996

16. de Ridder-Sluiter JG. Early detection of communicative disorders. XXV International Congress of Psychology; 19-24 July 1992; Brussels, Belgium: Lawrence Erlbaum Associates

17. de Ridder-Sluiter JG. Early Detection of Developmental Delays in Communication Abilities [in Dutch]. Leiden, Netherlands: Rijksuniversiteit Leiden; 1990

18. Bishop DVM. The biological basis of specific language impairment. In: Fletcher P, Hall D, eds. Specific Speech and Language Disorders in Children: Correlates, Characteristics and Outcomes. London, United Kingdom: Whurr Publishers; 1991:2-17

19. Stanton-Chapman TL, Chapman DA, Bainbridge NL, Scott KG. Identification of early risk factors for language impairment. Res Dev Disabil. 2002;23:390-405

20. Verhoeven LTW. Vocabulary Test, Manual [in Dutch]. Arnhem, Netherlands: Cito; 1996

21. Verhoeven LTW. Test of Progress in Spelling Skills, Manual [in Dutch]. Arnhem, Netherlands: Cito; 1997

22. Verhoeven LTW. Reading Comprehension, Manual [in Dutch]. Arnhem, Netherlands: Cito, 1997

23. Verhoeven LTW, Vermeer A. Language Test All Children, Assessment of Oral Language Skills Dutch for Children in Group 1-4 [in Dutch]. Arnhem, Netherlands: Citogroep, 2001

24. Verhoeven LTW. Three-Minutes Test (Technical Reading) [in Dutch]. Arnhem, Netherlands: Cito; 1997

25. Donner A. Some aspects of the design and analysis of cluster randomization trials. Appl Stat. 1998;47:95-113

26. Diez Roux AV. A glossary for multilevel analysis. J Epidemiol Community Health. 2005;56:588-594

27. Bland JM, Altman DG. One and two sided tests of significance. BMJ. 1994;309:248

28. Droop M, Verhoeven L. Language proficiency and reading ability in first- and second-language learners. Read Res Q. 2003; 38:78-103

29. Klee T, Pearce K, Carson DK. Improving the positive predictive value of screening for developmental language disorder. $J$ Speech Lang Hear Res. 2000;43:821-833

30. Stott CM, Merricks MJ, Bolton PF, Goodyer IM. Screening for speech and language disorders: the reliability, validity and accuracy of the General Language Screen. Int J Lang Commun Disord. 2002;37:133-151

31. Westerlund M. Relationship between a global rating of speech ability at the age of 3 yrs and a phonological screening $1 \mathrm{yr}$ later: a prospective field study. Scand J Caring Sci. 2001;15(3): 222-227 


\section{A Cluster-Randomized Trial of Screening for Language Delay in Toddlers:}

Effects on School Performance and Language Development at Age 8

Heleen M.E. van Agt, Heleen A. van der Stege, Hanneke de Ridder-Sluiter, Ludo T.

W. Verhoeven and Harry J. de Koning

Pediatrics 2007;120;1317

DOI: $10.1542 /$ peds. 2006-3145

\section{Updated Information \& Services}

References

Citations

Subspecialty Collections

Permissions \& Licensing

Reprints including high resolution figures, can be found at: http://pediatrics.aappublications.org/content/120/6/1317.full.h tml

This article cites 21 articles, 7 of which can be accessed free at:

http://pediatrics.aappublications.org/content/120/6/1317.full.h tml\#ref-list-1

This article has been cited by 8 HighWire-hosted articles: http://pediatrics.aappublications.org/content/120/6/1317.full.h tml\#related-urls

This article, along with others on similar topics, appears in the following collection(s):

Office Practice

http://pediatrics.aappublications.org/cgi/collection/office_pra ctice

Information about reproducing this article in parts (figures, tables) or in its entirety can be found online at:

http://pediatrics.aappublications.org/site/misc/Permissions.xht $\mathrm{ml}$

Information about ordering reprints can be found online: http://pediatrics.aappublications.org/site/misc/reprints.xhtml

PEDIATRICS is the official journal of the American Academy of Pediatrics. A monthly publication, it has been published continuously since 1948. PEDIATRICS is owned, published, and trademarked by the American Academy of Pediatrics, 141 Northwest Point Boulevard, Elk Grove Village, Illinois, 60007. Copyright ( 2007 by the American Academy of Pediatrics. All rights reserved. Print ISSN: 0031-4005. Online ISSN: 1098-4275.

\section{American Academy of Pediatrics}

DEDICATED TO THE HEALTH OF ALL CHILDREN ${ }^{m}$ 